\title{
Why WIBA?
}

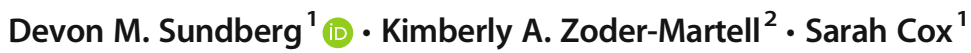

Published online: 11 June 2019

(C) Association for Behavior Analysis International 2019

\begin{abstract}
Historically, men have dominated the field of behavior analysis; however, recent trends have indicated increased participation by women. As a result of these recent changes to the field of behavior analysis, the inaugural Women in Behavior Analysis Conference (WIBA) was hosted in 2017. WIBA was initially established to highlight the accomplishments of women in the field of behavior analysis, to provide opportunities for early career behavior analysts to obtain mentorship, and to encourage meaningful discourse about gender issues in the field. Since the inaugural conference, WIBA has attempted to establish a platform for promoting gender equality but most recently has incorporated efforts related to the needs surrounding social justice and inclusiveness in the field of behavior analysis. The goal of this paper is to provide an overview of the WIBA conference. The history of WIBA is discussed, including the impetus for establishing the conference. This paper highlights existing issues on gender equality in the field of behavior analysis and the larger community, serves to demonstrate how WIBA is part of the solution, and shares accomplishments to date. Furthermore, future directions and goals are presented.
\end{abstract}

Keywords Advocacy $\cdot$ Gender $\cdot$ Social justice $\cdot$ Women

The first annual Women in Behavior Analysis (WIBA) conference was held in 2017 with the mission to empower, celebrate, and mentor women behavior analysts; to highlight their contributions to the field; and to engage both sexes in meaningful discourse on gender equality for the promotion of behavior analysis and the professional growth of future generations. This paper serves as a commentary made in real time on the establishment and early evolution of the WIBA conference.

The idea of WIBA originated while the first two authors were cochairing the 2016 annual conference of the Hoosier Association for Behavior Analysis (HABA). After noting a dearth of female invited speakers in other recently attended conferences, the cochairs generated an idea for the theme of the HABA conference to highlight the accomplishments of women in the field of behavior analysis. This idea came naturally and spontaneously to them, as they were both career women and mothers of daughters. Kim Zoder-Martell was

Devon M. Sundberg

Dsundberg@thebaca.com

1 Behavior Analysis Center for Autism, 9929 E. 126th St., Fishers, IN 46038, USA

2 Ball State University, 2000 W. University Ave, Muncie, IN 43036, USA employed as an assistant professor in the Department of Special Education at Ball State University. Devon Sundberg was the co-owner, with her husband, of an agency that provided applied behavior analysis (ABA) services to children with various disability conditions. The HABA organization declined to implement the idea of highlighting the influence of female behavior analysts for the state conference, so the cochairs decided to implement it independently in 2017 with the help of Marketing Director Sarah Cox. With the emerging political climate, feminism was in vogue, and quite honestly, it sounded like fun to host another conference together.

Although years of professional and personal experiences made us confident that the conference would be appealing to others, the acts of organizing and holding the conference illustrated quickly and definitely that this project was not just fun. It was serious in that many other professionals responded positively to the idea and conveyed a strong interest in celebrating the accomplishments of women in behavior analysis, as well as in analyzing and solving the common problems faced by women in the field. The concept generated interest, enthusiasm, and a commonly stated question from many wellmeaning behavior analysts: "Why WIBA?" To answer that question was a meaningful responsibility, and the opportunity for the conference to succeed and thrive depended in no small part on the answer. 


\section{Existing Issues on Gender Equality}

"Why WIBA?" is a direct, reasonable, and honest question. As the social climate began to unfold in 2016, it seemed that a portion of the voting populace of our generation realized how sheltered our perceptions of the world were. Every woman alive had the great fortune to miss the early struggle for gender equality (c. 1848), though many had been witness to the various battles for legal equality and for no discrimination on the basis of gender, including attaining credit in their own name, the right to attend all-male military schools or serve on the front lines, and the right to not face employment discrimination due to pregnancy (Carmon \& Knizhnik, 2015). Those battles resulted in progress for women and various underrepresented minority groups over the last 50 years. Unfortunately, it felt those accomplishments were beginning to unravel, especially in 2016. We realized that not everyone in the United States fully embraced a progressive state, and the struggle for social justice would, indeed, be a marathon rather than a recently completed sprint. There seemed to be a need for continued efforts in the area of gender equality, and WIBA was created, in part, to provide an outlet for that effort.

To assess the current professional needs of women in behavior analysis, we can begin by reviewing where the United States stands in overall gender equality in relation to other countries. Annually, the World Economic Forum (WEF) publishes a report titled Annually, the World Economic Forum (WEF) publishes The Global Gender Gap Index that currently ranks the United States as 51st out of 149 countries in the world (WEF, Project Team at the Centre for the New Economy and Society, 2018). The Global Gender Gap Index (GGGI) examines the gap between men and women in four fundamental categories: economic participation and opportunity, educational attainment, health and survival, and political empowerment. Respectively, in those areas, the United States ranked 19th, 46th, 71st, and 98th. Although the United States ranked higher than the majority of countries, its rank has declined steadily through the years. In 2010, the United States was ranked 19th out of 134 countries.

These data on the GGGI are representative of various gender-based discrepancies in the field of behavior analysis, as well as in the United States. Although women have many of the same opportunities that men do (e.g., the opportunity to serve in the military, employment), women are still behind in several important aspects of professional career success, equality, and freedom in their personal lives. In founding WIBA, the concerns of the women in behavior analysis became painfully evident. They reported concerns ranging from microaggressions and salary disparities to sexual harassment, discrimination, and a range of other issues.

Although the body of literature regarding women's issues in behavior analysis is relatively meager (i.e., approximately 40 publications in academic journals over the past 40 years), two recent contributions are worthy of note. First, at the inaugural WIBA conference, Melissa Nosik presented her recent analysis of data on women's representation in various career milestones - including professional recognition (e.g., awards, appointments), professional organization leadership, invited presentations, editorial board appointments, publication trends, faculty hires, and certification - and shared an overall career milestone analysis (Nosik, Luke, \& Carr, 2018). Nosik et al. (2018) found women were underrepresented in the categories of professional recognition, invited presentations, and editorial board appointments. Between 2012 and 2016, women earned $17.2 \%$ of later career awards and $35 \%$ of earlier career awards. Women represented $27.9 \%$ of invited presentations at the meetings of the Association for Behavior Analysis International (ABAI), the Association of Professional Behavior Analysts, the Berkshire Association for Behavior Analysis and Therapy, and the California Association for Behavior Analysis from 2014 to 2016. Despite being underrepresented, women's participation showed dramatic growth in editorial board appointments and publication trends. From 1978 to 2016, the percentage of women authors increased in the Journal of Applied Behavior Analysis (JABA) from 17.7\% to $61.5 \%$ and in the Journal of the Experimental Analysis of Behavior (JEAB) from $7.0 \%$ to $35.2 \%$; however, a decrease was noted in The Behavior Analyst (TBA) from 27.0\% to 24.2\% (Nosik et al., 2018). From 1979 to 2016, JABA increased women editorial board members from $25 \%$ to $41 \%$, and JEAB increased representation from $7.7 \%$ to $29.4 \%$. The year 2019 marks the first year that both JABA and JEAB employed female editors in chief, with Amy Odum finishing her term at JEAB and Linda LeBlanc beginning her term at JABA 1 year early. However, TBA's editorial board's representation of women decreased from $50 \%$ to $30.4 \%$.

Li, Curiel, Pritchard, and Poling (2018) added to this body of literature and shared women's contributions in authorship and editorial appointments in JABA, JEAB, Behavior Analysis in Practice, Behavior Analysis: Research and Practice, The Psychological Record, The Analysis of Verbal Behavior, and TBA. Across all journals, the mean percentage of women editors was $37.7 \%$ and the mean percentage of first authors who were women was $42.7 \%$. These data are comparable to or better than other fields, including the hard sciences, social sciences, and health fields, and humanities (Helmer, Schottdorf, Neef, \& Battaglia, 2017).

The primary findings of Nosik et al. (2018) and Li et al. (2018) focused on the publication and editorial trends of the scientific community of behavior analysis. Although these data are encouraging and demonstrate gains toward parity, Nosik et al. (2018) anchored their data in relation to age cohorts and career milestones often associated with later career achievement. These findings yield little information regarding milestones of early career women behavior analysts, as well as the practice community. In addition, although women's 
participation in scholarly publications and editorial trends in behavior analysis are increasing, it may not be increasing at the rate of the practice community. Given that $88 \%$ of Board Certified Behavior Analysts in 2016 were female (Nosik et al., 2018), it is conceivable that publication rates and participation on editorial boards should be greater. It is important that the behavior-analytic community ensures that women attain the skills to access the opportunities where female representation has been lagging.

Historically, other professions have attempted to meet this need to support women in developing skills to attain higher career status through professional associations for women. For example, the mission statement of the American Business Women's Association (incorporated in 1949) reads, "to bring together business women of diverse occupations and to provide opportunities for them to help themselves and others grow personally and professionally through leadership, education, networking support and national recognition." (https://www.abwa. org/about-us/, Mission Statement). The Accounting and Financial Women's Alliance, founded in 1938, has a mission to "enable women in all accounting and finance fields to achieve their full potential and to contribute to their profession." (https:// www.afwa.org/about/, Our Story). Perhaps most closely related to behavior analysis would be the field of psychology, whose professionals established the Association for Women in Psychology (AWP) in 1969. Their mission states,

AWP is a diverse feminist community of psychologists and allied professionals invested in the integration of personal, professional, and political power in the service of social justice. We challenge unexamined privilege and dominant discourses that marginalize and oppress within psychology and the wider society. AWP accomplishes this by promoting feminist scholarship, teaching, practice, and networking, and through mentoring, activism, and influencing public policy. (https://www. awpsych.org/about.php, Mission Statement).

They incorporate 13 vision statements to accomplish their mission, which have commonalities with WIBA's vision statements, such as providing a forum to discuss feminist contributions to the field and being sensitive to and inclusive of people of all backgrounds.

Anecdotally, our WIBA attendees have shared concerns for our field including a lack of diversity, sexual harassment, a gender pay gap, the feminization of behavior analysis and the potential for poor compensation associated with this trend, the need to promote and celebrate accomplished women, the struggles with achieving work/life balance, and a lack of or slowing of progress in the overall movement for gender equality and diversity. The WIBA conference focuses on strategies for maintaining the gains that women have made in our field, for promoting gender equity and diversity in our field, for empowering women who experience adverse events such as sexual harassment or discrimination, and for creating resources for establishing important leadership repertoires and mentoring relationships. WIBA sets out to provide solutions through education, creating opportunities and examples for the promotion of diversity and equity among behavior analysts.

\section{Solutions}

\section{Education and Training}

Maria Ruiz's (1995, 1998, 2003) work on gender gives our field a body of literature that provides perspective on how gender is ubiquitous and subtle. She used the term gendering to refer to the behaviors we engage in related to gender stereotyping. Ruiz's work highlighted how gender affects our behavioral repertoires. We actively engage in gender stereotypes so frequently that they become cultural norms, such as assuming infant girls dressed in blue are boys and differentiating between boy toys and girl toys. Ruiz's work shows us how “gaining a deeper understanding of the control exerted by gendered cultural practices, in turn results in an enriched field" through enhancing our objectivity in our own clinical work (Ruiz, 2003 p. 12).

WIBA has attempted to promote an understanding of "gendered cultural practices" by providing education, training, and opportunities to discuss feminist issues in our field (Ruiz, 2003 p. 12). WIBA creates tracks to attract presentations that feature women in research, women's issues, professional issues, and diversity. Some of our previous presentations have included commentary on women's issues, such as "Ticking Clocks" by Hayes (2017), an invited address on work/life balance, and "Women in EAB: Representation in the Journal of the Experimental Analysis of Behavior," by Odum and Galizio (2017), an interesting examination of the sector of experimental analysis of behavior where women have been severely underrepresented through the years but are experiencing striking improvements. We had the privilege to highlight Taylor's (2018) research when she gave an invited address on "Training and Treating Wholeheartedly: Identifying a Role for Compassion Practices in the Profession of Behavior Analysis," where she shared findings that demonstrated the benefits of compassion on the sustainability of behavior analysis and our lives as professionals.

WIBA's audience is composed of forward-thinking social leaders who wish to nurture and lift up everyone, so it was no surprise the audience of WIBA drove us to address diversity and inclusion of all minority groups in our 2019 effort. In February 2019, we discussed topics such as cultural responsiveness with Alai-Rosales (2019) and how biases can affect the health of an organization with Houmanfar (2019). We attempted to gain perspective and promote equity with the breakout presentation titled "Black Women in Behavior Analysis: An 
Interactive Dialogue of Black Representation," by Jackson, Jennile, Sheibanee, Shorter, and Bouie-Lindsay (2019).

WIBA not only includes didactic commentary on social and professional issues but also is a place to learn how to address the issues and provide training so that the attendees are more likely to become stronger professionals. Some of our most essential professional trainings have included "Sexual Harassment in ABA: What to Do If You Are the Victim?" (Cordova \& Cruz, 2017), "Job Negotiation and the Gender Pay Gap" (Zarcone, 2017), and "Mastering Core Professional Skills for Success as a Behavior Analyst" (LeBlanc, Sellers, \& Gravina, 2018).

\section{Creating Opportunities}

Creating a level playing field for individuals has much to do with creating opportunities. In addition to providing education, WIBA creates opportunities to access resources by offering scholarships. We awarded 11 scholarships to students in 2018. In 2019, we awarded 20 scholarships to female students and professionals of various ethnicities, races, gender identities, and sexual orientations. In addition to financial constraints, family responsibility is often cited as a barrier to women's professional success. For WIBA 2019, Portia ABA has agreed to sponsor WIBA's first on-site childcare facility. And, as always, we will have a mother's room for convenient pumping.

Other important opportunities are provided to our attendees through mentorship. WIBA creates opportunities for formal and informal mentorship and has also included presentations on the role of mentorship (Esch, 2017; LeBlanc, 2017; LeBlanc, McSweeney, Odum, Sandoz, Tarbox, ZoderMartell, \& Zarcone, 2017). Annually, the conference includes formal mentoring sessions between early career professionals or students and accomplished behavior analysts, such as the invited speakers, advisory board members, and volunteer organizations in small-group and individual mentoring sessions. The 2019 mentoring session accepted 36 mentees. Another structured mentorship opportunity occurs through our annual expert panel session. Invited speakers and members of our advisory board answer questions and provide feedback to attendees on their own greatest struggles and best advice. Our 2019 expert panel was titled "Leaders in Diversity, Respect and Inclusion" and was moderated by Jennifer Zarcone (AlaiRosales et al., 2019).

Informal mentoring is also encouraged and possible through several social events. Over a glass of wine, we've heard about some of Rita Gardner's (executive director, Melmark) greatest professional struggles, how Linda LeBlanc addressed a colleague behaving badly at a conference (note that not everyone can or should do this), and how Linda Hayes would bring her daughter to her office hours because she had to simultaneously fulfill her professional and personal responsibilities. At WIBA you can establish a relationship with someone who has been there and can tell you, "You've got this, but if you get in trouble, call me."

\section{Creating Examples}

Although WIBA is still in its infancy, the organization is committed to engaging in practices that other organizations may find beneficial to implement (e.g., incorporating on-site childcare for events, offering scholarships to women and minorities, establishing tracks on diversity and inclusion, ensuring fair and representative selection processes for prestigious opportunities). Many individuals and companies have already demonstrated an interest in and support for WIBA's mission. The organization vision statements have evolved to describe behaviors that support a more equitable professional landscape:

Hosting an annual conference that features notable contributions of women in the field of behavior analysis, ensuring that women are respected as scientists and leaders. Empowering early career behavior analysts through highlighting role models for those building their career. Inviting male speakers who support the effort of gender equality in the field of applied behavior analysis. Remaining informed of the current literature regarding the equitable representation of women in the field of behavior analysis.

Creating a network of support that will extend from our conference for women of color in the field of behavior analysis to eliminate barriers. (https://thebaca.com/ event/women-in-behavior-analysis-wiba-conference/), (https://thebaca.com/about-wiba/, About Us).

\section{Accomplishments}

To date, WIBA has brought together forward-thinking behavior analysts to shape and protect this effort. In 2017, we had an advisory board of three members and 250 attendees. Today, in 2019, the advisory board has grown to five esteemed colleagues willing to take on this duty and push WIBA's mission forward and 600 attendees. In 2017, attendees submitted 15 breakout sessions and all were accepted. In 2019, attendees submitted 70 presentations for only 30 available slots.

Mattaini (1996) suggested that a key element of creating social change requires identifying people in positions to initiate and implement behaviors and consequences to establish the new, preferred behaviors. WIBA would not have occurred in 2017, 2018, and now 2019 without the support and guidance of the advisory board. The advisory board members are Jennifer Zarcone (2016-present), Amy Odum (2016-present), 
Jonathan Tarbox (2016-present), Linda LeBlanc (2017-present), and Martha Pelaez (2018-present). In addition to serving on WIBA's advisory board, Jennifer Zarcone and Jonathan Tarbox have contributed to a diversity policy for ABAI. Linda LeBlanc has been appointed JABA's fourth female editor. Amy Odum, Jennifer Zarcone, and Linda LeBlanc aided in the creation of the Society for the Experimental Analysis of Behavior Graduate Student Diversity Scholarship, a financial opportunity for underrepresented individuals in our field. Jennifer Zarcone guest edited the special issue of Behavior Analysis in Practice on inclusion and diversity. Perhaps WIBA has contributed to the momentum of their efforts toward cultural change by providing access to material and creating connections that they can disseminate through other outlets.

In keeping with the effort to use behavior analysis to better the world, WIBA creates a space to discuss not only professional issues, and not only how we use behavior analysis to address those professional issues, but also how we use behavior analysis to address women's issues, which are human issues. For example, we heard from Traub (2018) on "The Role of Vision in the Development of Tactile Discrimination Skills for Breast Self-Examination" and Rey (2018) on "Increasing Effective Contraceptive Use Among Opioid-Maintained Women at Risk for Unintended Pregnancy."

Besides growth and tackling social issues, one of WIBA's proudest accomplishments is creating an environment where we can highlight the work of true examples in our field, as well as women who may not have received their fair recognition. WIBA can be a forum to archive women's contributions to our science throughout history. For example, Morris (2018) presented "On the History of Women in Behavior Analysis" and shared with us stories and struggles from some of our founding mothers, including Eve Segal and Ellen Reese. Segal was a student of B. F. Skinner and completed her PhD under the study of Kenneth MacCorquodale. In her 50th year as a behavior analyst, she was invited by the American Psychological Association (APA) to give an address where she shared the struggles of being a woman in science (Gilbert, 2017). Reese taught at Mount Holyoke College her entire career and holds a place on APA's "100 Most Important Women in Psychology" (ABAI, 2019). Also, Dickson, Berens, Whitehouse, and Shaw (2018) paid tribute to Maria Ruiz in their presentation "On the Life and Work of Maria Ruiz."

Our goal for the future is to sustain these efforts. Someone once stated that "WIBA built a culture of love, courage and vulnerability from the first moment of the first conference. I was genuinely moved by how brave and vulnerable people were, from accomplished professionals to new ABA therapists." J. Tarbox, personal communication, September 15, 2018). It is our hope that the field and the professionals within will embrace this mission, allowing slow and sustained growth. The WIBA conference benefits from and evolves based on an active advisory board gathering and implementing extensive feedback from our attendees, attracting a diverse audience, and collecting data to correlate with cultural outcomes. To determine the contributions of WIBA to the promotion of gender equality in the field of behavior analysis, we have identified some measurables to begin collecting data on. These include the number of conference scholarships or grants awarded to women and minorities in the field, childcare offered at conferences, WIBA attendance, ABAI fellowships awarded to women, the number of male attendees at WIBA, the number of attendees from minority groups at WIBA, speaking invitations for women in our field, the number of WIBA sponsors, and the number of organizations who adopt similar missions and efforts. Encouraging such efforts can help serve WIBA's mission. In the future, we also wish to expand our scholarship program by increasing the amounts awarded to cover the additional costs of attending conferences, especially the cost of childcare.

\section{Conclusion}

The GGGI indicated that the United States has room for growth in the areas of women's economic participation and opportunity, educational attainment, health and survival, and political empowerment (WEF, Project Team at the Centre for the New Economy and Society, 2018). Even with the paucity of research regarding feminist issues in our field, a similar pattern is evident in the field of behavior analysis. Women's participation has strengthened, but women are not yet fully empowered and represented in the prestigious echelons of behavior analysis. In a document created by the United Nations (United Nations, Task Force on the Implementation of the ICPD Programme of Action, 1995), the social construct of women's empowerment is described as having

five components: women's sense of self-worth; their right to have and to determine choices; their right to have access to opportunities and resources; their right to have the power to control their own lives, both within and outside the home; and their ability to influence the direction of social change to create a more just social and economic order, nationally and internationally. (p. 3)

During this very uncertain time in history, the profession of behavior analysis can take pride in the gathering and organization of the attendees, contributors, and advisors of the WIBA conference and the progressive topics discussed there. The energy has led to an educational experience that allows professionals to cultivate their sense of self-worth, to establish skills that will allow them to have and make more choices to control their professional lives, to access opportunity and 
mentorship, and to help better the world through behavior analysis. The growing WIBA experience demonstrates that women are here, are well equipped to lead and succeed, and can serve as an empowering support community for each other and other groups that experience issues of social injustice.

\section{Compliance with Ethical Standards}

Conflict of interest Devon Sundberg is the Co-founder and Conference Director of WIBA and has a financial interest in WIBA since 2017. Kimberly Zoder-Martell is the Co-founder of WIBA and had a financial interest in 2017, but has received no monetary incentives since that time and declared no current conflict of interest. Sarah Cox is the Marketing Director of WIBA and has received financial incentives for WIBA since 2017.

Ethical Approval This article does not contain any studies with human participants performed by any of the authors.

\section{References}

ABWA's Mission (n.d.). Retrieved June 3, 2019, from https://www.abwa. org/about-us/.

Accounting \& Financial Women's Alliance (n.d.). Retrieved June 3, 2019, from https://www.afwa.org/about/.

Association for Women in Psychology (n. d.). Retrieved June 3, 2019, from https://www.awpsych.org/about.php.

Alai-Rosales, S. (2019, February). Culture, social justice and the discipline of behavior analysis. Paper presented at the Women in Behavior Analysis Conference, Nashville, TN.

Alai-Rosales, S., Houmanfar, R., Kazemi, E., Mattaini, M., Pilgrim, C., \& Sellers, T. (2019, February). In J. Zarcone (Chair), Leaders in diversity, respect and inclusion. Panel conducted at the Women in Behavior Analysis Conference, Nashville, TN.

Carmon, I., \& Knizhnik, S. (2015). Notorious RBG. New York, NY: HarperCollins.

Cordova, K., \& Cruz, Y. (2017, March). Sexual harassment in ABA: What to do if you are the victim? Paper presented at the Women in Behavior Analysis Conference, Nashville, TN.

Dickson, C., Berens, K., Whitehouse, C., \& Shaw, S. (2018, March). On the life and work of Maria Ruiz. Paper presented at the Women in Behavior Analysis Conference, Nashville, TN.

Esch, B. (2017, March). Living a behavior analytic life: Lessons from my mentors. Paper presented at the Women in Behavior Analysis Conference, Nashville, TN.

Gilbert, R. (2017). Evalyn Finn Segal, in memoriam. Journal of the Experimental Analysis of Behavior, 107, 203-207. https://doi.org/ 10.1002/jeab.248.

Hayes, L. (2017, March). Ticking clocks. Paper presented at the Women in Behavior Analysis Conference, Nashville, TN.

Helmer, M., Schottdorf, M., Neef, A., \& Battaglia, D. (2017). Gender bias in scholarly peer review. eLife, 217, 1-18.

Houmanfar, R. (2019, February). Paper presented at the Women in Behavior Analysis Conference, Nashville, TN.

(Retrieved from, https://www.abainternational.org/constituents/bios/ ellenreese.aspx)

Jackson, K. L., Jennile, D., Sheibanee, D. B., Shorter, D., \& BouieLindsay, K. (2019, February). Black women in behavior analysis: An interactive dialogue of Black representation. Paper presented at the Women in Behavior Analysis Conference, Nashville, TN.
LeBlanc, L. (2017, March). The role of mentoring and career blazing in behavior analysis. Paper presented at the Women in Behavior Analysis Conference, Nashville, TN.

LeBlanc, L., McSweeney, F., Odum, A., Tarbox, J., \& Zoder-Martell, K. (2017, March). In J. Zarcone (Chair), The importance of mentorship for women in behavior analysis and gender issues in the field. Panel presented at the Women in Behavior Analysis Conference, Nashville, TN.

LeBlanc, L., Sellers, T., \& Gravina, N. (2018, March). Mastering core professional skills for success as a behavior analyst. Paper presented at the Women in Behavior Analysis Conference, Nashville, TN.

Li, A., Curiel, H., Pritchard, J., \& Poling, A. (2018). Participation of women in behavior analysis research: Some recent and relevant data. Behavior Analysis in Practice, 11, 160-164. https://doi.org/ 10.1007/s40617-018-0211-6

Mattaini, M. A. (1996). Finding solutions to social problems: Behavioral strategies for change. In M. A. Mattaini \& B. A. Thyer (Eds.), "Acting to save the world": The elements of action (pp. 397-412). Washington, DC: American Psychological Association.

Morris, E. (2018, March). On the history of women in behavior analysis. Paper presented at the Women in Behavior Analysis Conference, Nashville, TN.

Nosik, M. R., Luke, M. M., \& Carr, J. E. (2018). Representation of women in behavior analysis: An empirical analysis. Behavior Analysis: Research and Practice,. 19(2), 213-221. https://doi.org/ 10.1037/bar0000118.

Odum, A., \& Galizio, A. (2017, March). Women in EAB: Representation in the Journal of the Experimental Analysis of Behavior. Paper presented at the Women in Behavior Analysis Conference, Nashville, TN.

Rey, C. (2018, March). Increasing effective contraceptive use among opioid-maintained women at risk for unintended pregnancy. Paper presented at the Women in Behavior Analysis Conference, Nashville, TN.

Ruiz, M. R. (1995). B. F. Skinner's radical behaviorism: Historical misconstructions and grounds for feminist reconstruction. Psychology of Women Quarterly, 19, 161-179. https://doi.org/10.1111/j.14716402.1995.tb00285.x.

Ruiz, M. R. (1998). Personal agency in feminist theory: Evicting the elusive dweller. The Behavior Analyst, 21, 179-192. https://doi. org/10.1007/BF03391962.

Ruiz, M. R. (2003). Inconspicuous sources of behavioral control: The case of gendered practices. The Behavior Analyst Today, 4, 12-16. https://doi.org/10.1037/h0100005

Taylor, B. (2018, March). Training and treating wholeheartedly: Identifying a role for compassion practices in the profession of behavior analysis. Paper presented at the Women in Behavior Analysis Conference, Nashville, TN.

Traub, M. (2018, March). The role of vision in the development of tactile discrimination skills for breast self-examination. Paper presented at the Women in Behavior Analysis Conference, Nashville, TN.

United Nations, Task Force on the Implementation of the ICPD Programme of Action. (1995). Guidelines on women's empowerment for the UN Resident Coordinator System. Retrieved from http://www.un.org/popin/unfpa/taskforce/guide/iatfwemp.gdl.html

World Economic Forum, Project Team at the Centre for the New Economy and Society. (2018). The Global Gender Gap Report. Retrieved from http://www3.weforum.org/docs/WEF_GGGR 2018.pdf

Zarcone, J. (2017, March). Job negotiation and the gender pay gap. Paper presented at the Women in Behavior Analysis Conference, Nashville, TN.

Publisher's Note Springer Nature remains neutral with regard to juris dictional claims in published maps and institutional affiliations. 